\title{
Lusioersily
}

\section{Threshold limit of postoperative astigmatism for patient satisfaction after refractive lens exchange and multifocal intraocular lens implantation}

McNeely, R., Pazo, E., Millar, Z., Richoz, O., Nesbit, M. A., Moore, C. B. T., \& Moore, J. E. (2016). Threshold limit of postoperative astigmatism for patient satisfaction after refractive lens exchange and multifocal intraocular lens implantation. Journal of Cataract and Refractive Surgery, 42(8), 1126-1134.

https://doi.org/10.1016/j.jcrs.2016.05.007

Link to publication record in Ulster University Research Portal

Published in:

Journal of Cataract and Refractive Surgery

Publication Status:

Published (in print/issue): 13/08/2016

DOI:

10.1016/j.jcrs.2016.05.007

Document Version

Author Accepted version

\section{General rights}

Copyright for the publications made accessible via Ulster University's Research Portal is retained by the author(s) and / or other copyright owners and it is a condition of accessing these publications that users recognise and abide by the legal requirements associated with these rights.

\section{Take down policy}

The Research Portal is Ulster University's institutional repository that provides access to Ulster's research outputs. Every effort has been made to ensure that content in the Research Portal does not infringe any person's rights, or applicable UK laws. If you discover content in the Research Portal that you believe breaches copyright or violates any law, please contact pure-support@ulster.ac.uk. 
Cataract \& Refractive Surgery

Elsevier Editorial System(tm) for Journal of Manuscript Draft

Manuscript Number: JCRS-16-338R1

Title: Threshold limit of postoperative astigmatism for patient satisfaction after clear lens extraction and multifocal intraocular lens implantation

Article Type: Full Length Article

Section/Category: Refractive

Keywords: Multifocal Intraocular Lens; Astigmatism

Corresponding Author: Professor jonathan E Moore, ERCophth, PhD

Corresponding Author's Institution: Mater Hospital

First Author: Jonathan E Moore

Order of Authors: Jonathan E Moore; McNeely Richard; Eric Pazo; Andrew Spence; Zack Millar; Olivier Richoz; Andrew Nesbit; Tara Moore

Abstract: PURPOSE: To determine the degree of tolerance towards different magnitudes of residual refractive and corneal astigmatism, and angles of corneal astigmatism following implantation of an asymmetric multifocal intraocular lens (MIOL).

SETTING/VENUE: Cathedral Eye Clinic, Belfast, Northern Ireland, UK

DESIGN: Retrospective comparative case series.

METHODS: The study enrolled 117 patients (234 eyes) with a mean age of 64 years undergoing clear lens extraction (CLE) and implantation of a lentis Mplus LS-312 MF30 MIOL. Refraction, uncorrected (UDVA) and best-corrected (CDVA) distance visual acuities, uncorrected near (UNVA) and intermediate (UIVA) visual acuities, and a quality of vision (QOV) questionnaire were evaluated. Groups were categorised based upon the magnitude of residual refractive astigmatism and secondly on postoperative corneal astigmatism. The groups were $50.50 \mathrm{D}$, and $>0.50 \mathrm{D}$ of residual refractive astigmatism and $\leq 0.50 \mathrm{D}, 0.51 \mathrm{D}$ to $0.75 \mathrm{D}, 0.76 \mathrm{D}$ to $1.00 \mathrm{D},>1.00 \mathrm{D}$ of corneal astigmatism.

RESULTS: There was a significant difference in UDVA ( $P=0.003)$, refractive sphere $(P=0.001)$ and defocus equivalent $(P=<0.001)$ between residual refractive astigmatism groups, but no difference in QOV ( $\mathrm{P}=0.28)$. The same was found for corneal astigmatism with UDVA $(P=<0.001)$ and QOV $(\mathrm{P}=0.16)$. The angle of corneal astigmatism in relation to inferior nasal placement of the near segment did not statistically affect visual and subjective outcomes.

CONCLUSIONS: The Lentis Mplus MIOL appears to subjectively tolerate well residual refractive and corneal astigmatism despite a statistically significant difference in UDVA with higher magnitudes of residual astigmatism. The angle of residual corneal astigmatism in relation to 
MIOL placement does not have a significant effect on objective or subjective outcomes. 
Title:

Threshold limit of postoperative astigmatism for patient satisfaction after clear lens extraction and multifocal intraocular lens implantation

\section{Short Running Head:}

Threshold limit of MIOL to residual astigmatism

\section{Authors:}

Mr Richard N McNeely BSc ${ }^{1,2}$, Dr Eric Pazo MD ${ }^{1,2}$, Mr Andrew Spence BSc ${ }^{1}, \mathrm{Mr}$ Zack Millar ${ }^{1}$, Dr Olivier Richoz MD PhD ${ }^{1}$, Dr Andrew Nesbit BA, PhD², Professor Tara CB Moore $\mathrm{PhD}^{2}$ and Professor Jonathan E Moore PhD FRCOphth ${ }^{1,2}$

1 Cathedral Eye Clinic, Belfast Campus, University of Ulster, Belfast, UK.

2 Biomedical Sciences Research Institute, University of Ulster, Coleraine, UK.

Prior Presentation: None

Financial Support: None

The authors' have no financial or proprietary interest in a product, method, or material, or lack thereof.

Name and address of author to receive reprint requests:

Professor Jonathan E Moore, Cathedral Eye Clinic, 89-91 Academy Street, Belfast, County Antrim, BT1 2 LS. jmoorecathedral@gmail.com 


\section{Abstract}

PURPOSE: To determine the degree of tolerance towards different magnitudes of residual refractive and corneal astigmatism, and angles of corneal astigmatism following implantation of an asymmetric multifocal intraocular lens (MIOL).

SETTING/VENUE: Cathedral Eye Clinic, Belfast, Northern Ireland, UK

DESIGN: Retrospective comparative case series.

METHODS: The study enrolled 117 patients (234 eyes) with a mean age of 64 years undergoing clear lens extraction (CLE) and implantation of a Lentis Mplus LS-312 MF30 MIOL. Refraction, uncorrected (UDVA) and best-corrected (CDVA) distance visual acuities, uncorrected near (UNVA) and intermediate (UIVA) visual acuities, and a quality of vision (QOV) questionnaire were evaluated. Groups were categorised based upon the magnitude of residual refractive astigmatism and secondly on postoperative corneal astigmatism. The groups were $\leq 0.50 \mathrm{D}$, and $>0.50 \mathrm{D}$ of residual refractive astigmatism and $\leq 0.50 \mathrm{D}, 0.51 \mathrm{D}$ to $0.75 \mathrm{D}, 0.76 \mathrm{D}$ to $1.00 \mathrm{D},>1.00 \mathrm{D}$ of corneal astigmatism.

RESULTS: There was a significant difference in UDVA ( $P=0.003)$, refractive sphere $(P=0.001)$ and defocus equivalent $(P=<0.001)$ between residual refractive astigmatism groups, but no difference in QOV $(P=0.28)$. The same was found for corneal astigmatism with UDVA $(P=<0.001)$ and QOV $(P=0.16)$. The angle of corneal astigmatism in relation to inferior nasal placement of the near segment did not statistically affect visual and subjective outcomes. 
CONCLUSIONS: The Lentis Mplus MIOL appears to subjectively tolerate well

residual refractive and corneal astigmatism despite a statistically significant difference in UDVA with higher magnitudes of residual astigmatism. The angle of residual corneal astigmatism in relation to MIOL placement does not have a significant effect on objective or subjective outcomes. 


\section{Introduction}

Multifocal intraocular lens (MIOL) technology is often utilised in modern cataract extraction surgery and refractive procedures, providing excellent levels of visual performance at a range of distances ${ }^{1-4}$ and spectacle independence. ${ }^{5,6}$ However not all individuals are content postoperatively. Reported problems include reduced contrast, glare, haloes and/or starbursts around lights. ${ }^{1,7}$ Patients may also report substandard near or intermediate vision which affects their ability to see clearly at different working distances. ${ }^{8,9}$ It is important to consider what produces these negative side effects and reduces overall patient satisfaction. One factor that appears to affect postoperative vision and quality of life is uncorrected astigmatism. ${ }^{10}$ Various MIOL studies have found patient complaints of blurred vision, which in the majority of cases has been caused by ametropia and / or astigmatism, a wellrecognised cause of patient dissatisfaction with symmetric MIOLs. ${ }^{11,12}$ The effect of astigmatism upon uncorrected distance visual acuity has been shown to have a greater effect in symmetric MIOLs compared to monofocal IOLs. ${ }^{13}$

Rotationally asymmetric MIOLs have since been introduced which differ from rotationally symmetric MIOLs, as they only possess two sections, a surfaceembedded near section and a larger distance section, providing two different foci opposed to concentric rings in previous MIOL design. With only two transition zones, rotationally asymmetric MIOLs provide excellent visual results and reduce dysphotopsic side effects ${ }^{14}$ and improve contrast sensitivity. ${ }^{15}$ 
To our knowledge the effect of uncorrected residual astigmatism on this new asymmetric MIOL design has not been investigated. Therefore, this study sought to determine and quantify, where possible, the effect of residual refractive astigmatism upon subjective QOV following the implantation of an asymmetric MIOL. The effect of postoperative corneal astigmatism and the relationship between the MIOL position compared to the angle of the steepest corneal meridian, upon subjective QOV was also measured. The aim of this study is to determine the degree of tolerance patients have to different levels of residual astigmatism and to the angle of this astigmatism with relation to the position of the asymmetric MIOL, before there is a significant deleterious impact upon QOV.

\section{Patients and Methods}

This study enrolled patients undergoing clear lens extraction (CLE) with bilateral implantation of Lentis Mplus MIOLs. Patients were first divided into two groups depending on the magnitude of residual refractive astigmatism found following subjective refraction. The two groups were $\leq 0.50 \mathrm{D}$ and $>0.50 \mathrm{D}$. Patients were then categorised based on the magnitude of postoperative corneal astigmatism into 4 groups. The groups were $\leq 0.50 \mathrm{D}, 0.51 \mathrm{D}$ to $0.75 \mathrm{D}, 0.76 \mathrm{D}$ to $1.00 \mathrm{D},>1.00 \mathrm{D}$. The postoperative corneal astigmatism was measured using the NIDEK OPD-Scan II ARK-10000 aberrometer. The magnitude of corneal astigmatism was defined as the difference between the steep and flat corneal meridians. Patients with corneal astigmatism $>0.50 \mathrm{D}$ were then categorised by the angle of the steepest corneal meridian in relation to the position of the MIOL (Figure 1). Preoperatively at the slitlamp the horizontal and vertical axis were marked at the limbus. The MIOL was 
implanted with the near segment positioned inferiorly and nasally deviated half way between the vertical and horizontal 'limbal marks'. Therefore, the long axis of the MIOL was positioned around 135 degrees in the right eye and 45 degrees in the left eye. Patients with the steepest meridian between 0 to 22.5 degrees, 158 to 180 degrees, and 68 to 112.5 degrees in either the right or left eye were considered to obliquely cross the vertical axis. Patients with the steepest meridian at an angle of 23 to 67.5 degrees in the right eye and an axis of 113 to 157.5 degrees in the left eye were categorised together because they both crossed perpendicularly to the vertical axis. Patients with an axis of 113 to 157.5 degrees in the right eye and 23 to 67.5 degrees in the left were grouped together because the steepest meridian ran parallel to the vertical axis in the respective eyes.

Informed consent was obtained from all patients. The research adhered to the tenets of the Declaration of Helsinki and was approved by the local research ethics committee. The patients were advised of the possible risks of the operation and the possible need for further corneal laser refractive surgery.

\section{Patient assessment}

Full ophthalmological assessment was performed preoperatively and postoperatively. The examination included a medical history, autorefraction (OPDScan II ARK-10000, Nidek), subjective refraction (RT-5100 Auto Phoropter Head Nidek), uncorrected (UDVA) and corrected (CDVA) distance visual acuities, defocus equivalent based on subjective refraction, uncorrected near (UNVA) and uncorrected intermediate (UIVA) visual acuities. These results were evaluated with logMAR 
charts $(6 \mathrm{~m})$ and with Radner reading charts in $M$ notation $(40 \mathrm{~cm}$ and $70 \mathrm{~cm})$. Biometry was carried out preoperatively with the IOLMaster (Carl Zeiss Meditec AG). Pupil size, corneal topography, angle kappa and wavefront examinations (OPD-Scan II ARK-10000, Nidek) were performed. The OPD-Station Software was utilised to report higher order aberrations (HOAs) across a $6 \mathrm{~mm}$ pupil up to the sixth radial order. $^{16}$ It has been found that aberrations above the sixth order have extremely small impact on the overall aberration. ${ }^{17}$ Slit-lamp microscopy, tonometry, dilated funduscopy, and OCT of the retina were completed. Each patient was assessed within 6 weeks and then 6 months postoperatively. The position of the vertical axis of the MIOL was assessed postoperatively to confirm an axis of 135 degrees in the right eye and 45 degrees in the left eye.

A quality of vision (QOV) questionnaire was completed preoperatively and at the second postoperative assessment. This assessed how annoyed the patients were by the questioned symptoms. Patients responded either not at all (0), a little (1), quite (2) or very (3). The patient also rated their vision out of 10; 0 representing the worst and 10 the best.

\section{Intraocular lenses}

The Lentis Mplus is a rotationally asymmetric MIOL consisting of an aspheric distance vision zone and a separate sector shaped near vision zone. It has a refractive design with seamless transition between the two sections of the MIOL. The Lentis Mplus MIOL is available with either a $+1.50 \mathrm{D},+2.00 \mathrm{D}$ or $+3.00 \mathrm{D}$ near 
segment addition. In this study each patient received bilateral implantation of the Lentis Mplus LS-312 MF30 (+3.00D addition).

\section{Surgical technique}

The same experienced surgeon performed all operations with standard on-axis clear corneal phacoemulsification surgery. An incision of $2.75 \mathrm{~mm}$ was used to reduce postoperative corneal astigmatism and the incision was made on the steepest meridian to evade the introduction of oblique astigmatism. A $5.00 \mathrm{~mm}$ capsulorhexis and implantation of the MIOL into the capsular bag was performed. The vertical axis (near segment) was positioned inferiorly with slight nasal deviation in each eye. The refractive aim was emmetropia.

\section{Statistical analysis}

Descriptive and statistical analysis was performed using SPSS for Windows (Statistical Package for the Social Sciences, Version 22, Chicago, Illinois, USA) and Excel (Microsoft; Redmond, Washington, USA). The Kolmogorov-Smirnov test was used to assess normality. Independent t tests and one way Anova were utilised for parametric data with a post hoc Tukey test to compare the results among groups. The Kruskall-Wallis test was used to compare nonparametric data and the Wilcoxon signed rank-test was used to compare nonparametric data among groups. A paired sample $\mathrm{t}$ test was also used to test the significance between preoperative and postoperative HOAs. For all statistical analysis, the level of significance was $\mathrm{P}<0.05$. 


\section{Results}

\section{Demographics}

This study included 117 patients (234 eyes) with a mean age of 64 years, ranging from 44 to 87 years (Table 1).

The magnitude of residual refractive astigmatism

Figure $2 \mathrm{a}$ displays the linear regression analysis between the residual refractive astigmatism and the UDVA, where a weak correlation was found $\left(R^{2}=0.12\right)$. Figure $2 \mathrm{~b}$ shows a slightly stronger association between UDVA and the defocus equivalent $\left(R^{2}=0.23\right)$. The patients were then divided into two groups. There were 216 eyes with $\leq 0.50 \mathrm{D}$ and 18 eyes with $>0.50 \mathrm{D}$ postoperative refractive cylinder. Table 2 displays the objective results for the different groups. The group with residual refractive astigmatism $\leq 0.50 \mathrm{D}$ achieved better UDVA than those with $>0.50 \mathrm{D}(P=0.003$, independent $t$ test). There was also a greater magnitude of defocus equivalent in the $>0.50 \mathrm{D}$ group $(\mathrm{P}=<0.001$, independent $\mathrm{t}$ test). Comparison of the individual symptom responses is highlighted in Figure 3 and the QOV scores in Figure 4. There was no significant difference in individual responses or QOV scores $(P=0.28$, independent $t$ test).

The magnitude of residual corneal astigmatism 
The different groups were $\leq 0.50 \mathrm{D}(\mathrm{n}=99), 0.51 \mathrm{D}$ to $0.75 \mathrm{D}(\mathrm{n}=53), 0.76 \mathrm{D}$ to $1.00 \mathrm{D}$ $(n=41)$ and $>1.00 D(n=41)$ of corneal astigmatism. The mean corneal astigmatism found postoperatively was $-0.63 \pm 0.36 \mathrm{D}$. Patients with $\leq 0.50 \mathrm{D}$ achieved UDVA of $0.07 \pm 0.08 \log M A R$ which was significantly better than those with $0.76 \mathrm{D}$ to $1.00 \mathrm{D}$ $(0 \pm 0.08 \log M A R)$ and $>1.00 \mathrm{D}(0 \pm 0.11 \log M A R)$, outlined in Table 3 . There was no significant difference in individual symptoms and overall QOV scores between the groups.

$\underline{\text { Residual corneal astigmatism axis in relation to the MIOL }}$

There were 135 eyes with corneal astigmatism >0.50D and 99 of these were in the oblique group, 22 in the perpendicular group and 14 in the parallel group. There was no significant difference in objective outcomes between eyes with varying angles of corneal astigmatism (Table 4). There were 60 patients with the steepest corneal meridian crossing the vertical axis of the MIOL in each eye, 13 patients with steepest corneal meridian crossing perpendicular to the vertical axis in each eye and 6 patients with a parallel relationship to the MIOL in each eye. There was no significant difference in individual questioned symptoms and overall QOV scores between the groups (Figure 5).

\section{Discussion}

It is common to have varying levels of residual astigmatism following lens replacement surgery and its magnitude can be difficult to predict due to multiple dependent factors. ${ }^{18}$ Residual refractive astigmatism affects visual acuity ${ }^{13,19}$ and is 
one of the main causes of blurred vision ${ }^{11,12}$ following implantation of both monofocal IOLs and MIOLs. However, it is not known how residual astigmatism affects asymmetric MIOLs. Therefore, this study sought to determine what effect residual refractive astigmatism and corneal astigmatism had upon QOV after implantation of an asymmetric Lentis Mplus MIOL.

The current study demonstrates there is a significant difference in UDVA between patients who have $\leq 0.50 \mathrm{D}$ compared to those with $>0.50 \mathrm{D}$ of residual refractive astigmatism. It was also observed that the defocus equivalent was greater in the $>0.50 \mathrm{D}$ group confirming that the defocus equivalent was not a significant cofounding factor to the effect of increasing cylinder upon UDVA (Table 2). There was no significant difference in either UNVA or UIVA between the two residual refractive astigmatism groups. With traditional symmetric MIOLs it has been found that the distance visual acuity is significantly affected by uncorrected astigmatism. Hayashi et $\mathrm{al}^{19}$ found that with $0.50 \mathrm{D}, 1.00 \mathrm{D}, 1.50 \mathrm{D}$ and $2.00 \mathrm{D}$ of simulated astigmatism distance visual acuity was significantly reduced at each magnitude of astigmatism with both $\mathrm{a}+3.00 \mathrm{D}$ and $+4.00 \mathrm{D}$ addition symmetric MIOL (AcrySof ReSTOR). The same was found for monofocal IOLs, however the reduction in distance visual acuity was worse with the MIOLs. There was no significant difference between the MIOLs and monofocal IOLs in distance visual acuity up to $1.00 \mathrm{D}$ and with astigmatism of $1.50 \mathrm{D}$ and greater the distance and intermediate vision was better with monofocal IOLs. The near visual acuity was significantly better with the MIOL group up to $1.00 \mathrm{D}$ of astigmatism. This study suggests that the MIOLs are useful up to $1.00 \mathrm{D}$ of astigmatism. Hayashi et $a 1^{13}$ found that with symmetric MIOLs (AMO Array) that the fraction of treated eyes able to achieve 0.16logMAR decreased 
for every $0.50 \mathrm{D}$ of astigmatism. Of the 30 eyes in their study, 24 achieved 20/29 $(0.16 \log M A R)$ and $20 / 50(0.40 \log M A R)$ with no astigmatism, 21 eyes with $0.50 \mathrm{D}$, 13 eyes with $1.00 \mathrm{D}, 8$ eyes with $1.50 \mathrm{D}$ and no eyes achieved this level of acuity with $2.00 \mathrm{D}$ and $2.50 \mathrm{D}$ of astigmatism. This study also compared these results to a monofocal IOL where they found that the MIOL group achieved a significantly worse distance visual acuity with $0.50 \mathrm{D}, 1.00 \mathrm{D}$ and $1.50 \mathrm{D}$ of astigmatism, however the near visual acuity was better in the MIOL group. With higher levels of astigmatism, $2.00 \mathrm{D}$ and $2.50 \mathrm{D}$ of astigmatism, the MIOL group showed significantly worse distance and intermediate visual acuity than the monofocal group. This study concludes that MIOLs are more affected by residual astigmatism than monofocal IOLs. These studies highlight that residual astigmatism has an effect on visual acuity at all distances however it appears the multifocality of MIOLs is not affected until astigmatism is greater than $1.00 \mathrm{D}$. It appears that monofocal IOLs are better at distance and intermediate when astigmatism is greater than $1.00 \mathrm{D}$. In our study there were only 18 eyes with astigmatism of $0.75 \mathrm{D}$ and greater because our refractive aim was emmetropia. This is one shortcoming of our study allowing only two separate groups of differing magnitudes of residual refractive astigmatism. It would be beneficial to have more groups to allow more detailed analysis between different magnitudes of astigmatism determining the exact level that begins to affect visual performance. However, it is clear from our study that there is a statistically significant difference in UDVA between the groups. Therefore, in this study it would appear that the objective UDVA is affected by increasing levels of astigmatism in a similar fashion to symmetric MIOLs, ${ }^{13}$ however the $>0.50 \mathrm{D}$ of residual refractive astigmatism group still displays an excellent level of unaided visual acuity. As discussed in the study by Hayashi et al $^{13}$ they report 21 eyes out of $30(70 \%)$ 
achieved distance visual acuity of $0.16 \log$ MAR for distance and $0.40 \log M A R$ for near with $1.00 \mathrm{D}$ and $1.50 \mathrm{D}$ of astigmatism. In our study 14 patients out of $18(77 \%)$ displayed distance and near visual acuity of this level with astigmatism of $0.75 \mathrm{D}$ and above. However, unlike previous studies of symmetric MIOLs, residual refractive astigmatism does not negatively affect UNVA and UIVA. ${ }^{19}$ Further analysis of objective findings with asymmetric MIOLs is required and direct comparison to both traditional symmetric MIOLs and monofocal IOLs would be beneficial.

Objective outcomes only give an indication of visual performance therefore we sought to determine how residual refractive astigmatism affected subjective outcomes through the use of a QOV questionnaire. Analysis of the individual symptoms investigated through the questionnaire in this study for each of the two refractive astigmatism groups are shown in Figure 3. There was no significant difference between the two groups for each of the questioned symptoms. In a study by de Vries et $\mathrm{al}^{11}$ of 76 eyes implanted with diffractive MIOLs in which $64.5 \%$ of patients complained of blurred vision due to ametropia or astigmatism. The overall mean refractive cylinder was $-0.95 \mathrm{D}$. In another study of 43 eyes with diffractive MIOLs $25 \%$ had residual astigmatism of $\geq 0.75 \mathrm{D}$, and patients that complained of blurred vision had mean astigmatism of $1.55 \mathrm{D}$ compared to the other patients where the mean astigmatism was $0.53 \mathrm{D} .^{12} \mathrm{~A}$ previous study found that patients with MIOLs and astigmatism $>1.00 \mathrm{D}$ reported significantly bigger haloes compared to individuals with astigmatism of $<1.00 \mathrm{D} .^{20}$ This contrasts with the findings from our study where there was no significant difference in subjective visual complaints, such as glare and dysphotopsias, between the groups. However our results with this asymmetric MIOL were in broad agreement with those of Dick et $\mathrm{al}^{20}$ which found that monofocal IOLs 
did not show a significant difference in frequency of reported haloes and glare between patients with $<1.00 \mathrm{D}$ and $>1.00 \mathrm{D}$ of astigmatism. An important aspect of the questionnaire used is that the patient is asked to report their overall QOV out of 10 . This provides an overall indication of how satisfied an individual is with their QOV. In this current study each group achieved excellent QOV scores with no significant difference between the groups. Although there is a significant difference in UDVA with higher residual refractive astigmatism, similar to symmetric MIOLs this is not reflected in individual symptom responses or the overall QOV scores. As there was only one case with higher levels of residual defocus equivalent $>1.50 \mathrm{D}$ it is difficult to know absolute patient tolerances, however no one in this cohort required further laser refractive surgery despite its free availability. It would appear that asymmetric MIOLs are subjectively more tolerant to higher degrees of astigmatism.

There was some disparity between the refractive astigmatism and the corneal astigmatism found postoperatively. This may be due to in part to measurement error or the MIOL internally affecting the total refractive astigmatism present. Accurate measurement of this however can be somewhat difficult with the OPD scan due to the inability of Zernike polynomials to adequately decompose wavefront aberrations from both the distance and juxtaposed near add. Characteristically this can be interpreted in the OPD as coma rather than simply an increase in spherical power in the near add. ${ }^{21}$ This current study only found a significant increase in trefoil aberrations when comparing preoperative to postoperative which again may be inaccurate and due to the aforementioned problems. We therefore assessed the isolated effect of corneal astigmatism upon objective outcomes and patient satisfaction. The mean corneal astigmatism found in this study was $-0.63 \pm 0.36 \mathrm{D}$ 
and is comparable to other studies where Elkady et $\mathrm{al}^{22}$ found the mean astigmatism to be $-0.63 \pm 0.62 \mathrm{D}$ after microincision cataract surgery. Our study showed that the level of UDVA was significantly worse than the $\leq 0.50 \mathrm{D}$ group when astigmatism was $0.76 \mathrm{D}$ to $1.00(P=<0.001)$ and $>1.00 \mathrm{D}(\mathrm{P}=<0.001)$ as outlined in table 3 , however again UDVA remained at an excellent clinical level. Similar to the previously assessed refractive astigmatism this difference in UDVA did not appear to affect the patient satisfaction as no significant difference was found between the postoperative corneal groups. Likewise with residual refractive astigmatism there was no significant difference in reports of blurred vision and haloes as previously found with increasing levels of induced astigmatism. ${ }^{11,12,20}$

We also sought to determine the effect of the axis of the corneal astigmatism in relation to the vertical axis of the asymmetric MIOL on postoperative objective and subjective outcomes. To our knowledge this is the first study to determine the effect of uncorrected astigmatism on asymmetric MIOLs and therefore the first study to determine the effect of the axis on postoperative outcomes. In this current study we found that the relation between the vertical axis of the MIOL and the corneal astigmatism did not have a significant effect on objective or subjective outcomes.

In summary this study highlights that asymmetric MIOLs are significantly affected by residual astigmatism for UDVA however UNVA and UIVA appears to be unaffected. Additionally, an increasing magnitude of residual astigmatism does not significantly affect subjective outcomes. Also when implanting an asymmetric MIOL inferiorly with nasal displacement the angle of the steepest corneal meridian in relation to this placement does not affect either objective outcomes or overall subjective QOV. This 
gives the clinician a better understanding of the effects of residual astigmatism after CLE on patient satisfaction and will help the surgeon decide on clinical management of residual astigmatism. 
What was known:

What this study added:

This rotationally asymmetric MIOL is not subjectively affected by increasing magnitudes of residual refractive or corneal astigmatism.

The angle of the residual corneal astigmatism in relation to the position of the MIOL does not affect objective outcomes and overall patient satisfaction. 


\section{References}

1. Leyland M, Zinicola E. Multifocal versus monofocal intraocular lenses in cataract surgery: A systematic review. Ophthalmology 2003;110(9):1789-1798.

2. Javitt JC, Steinert RF. Cataract extraction with multifocal intraocular lens implantation: A multinational clinical trial evaluating clinical, functional, and quality-oflife outcomes. Ophthalmology 2000;107(11):2040-2048.

3. Chiam PJT, Chan JH, Aggarwal RK, Kasaby S. ReSTOR intraocular lens implantation in cataract surgery: Quality of vision. J Cataract Refract Surg 2006;32(9):1459-1463.

4. Cillino S, Casuccio A, Di Pace F, et al. One-year outcomes with new-generation multifocal intraocular lenses. Ophthalmology 2008;115(9):1508-1516.

5. Lubinski W, Gronkowska-Serafin J, Podboraczynska-Jodko K. Clinical outcomes after cataract surgery with implantation of the tecnis ZMB00 multifocal intraocular lens. Med Sci Monitor 2014;20:1220-1226.

6. Zhang F, Sugar A, Jacobsen G, Collins M. Visual function and spectacle independence after cataract surgery: Bilateral diffractive multifocal intraocular lenses versus monovision pseudophakia. J Cataract Refract Surg 2011;37(5):853-858.

7. Montés-Micó R, Alió JL. Distance and near contrast sensitivity function after multifocal intraocular lens implantation1. J Cataract Refract Surg 2003;29(4):703711.

8. Hütz WW, MD, Eckhardt HB, MD, Röhrig B, Grolmus R, MD. Intermediate vision and reading speed with array, tecnis, and ReSTOR intraocular lenses. J Refract Surg 2008;24(3):251-6. 
9. Blaylock JF, Si Z, Vickers C. Visual and refractive status at different focal distances after implantation of the ReSTOR multifocal intraocular lens. J Cataract Refract Surg 2006;32(9):1464-1473.

10. Wolffsohn JS, Bhogal G, Shah S. Effect of uncorrected astigmatism on vision. J Cataract Refract Surg 2011;37(3):454-460.

11. de Vries NE, Webers $\mathrm{CAB}$, Touwslager $\mathrm{WRH}$, et al. Dissatisfaction after implantation of multifocal intraocular lenses. J Cataract Refract Surg 2011;37(5):859865.

12. Woodward MA, Randleman JB, Stulting RD. Dissatisfaction after multifocal intraocular lens implantation. J Cataract Refract Surg 2009;35(6):992-997.

13. Hayashi K, Hayashi H, Nakao F, Hayashi F. Influence of astigmatism on multifocal and monofocal intraocular lenses. Am J Ophthalmol 2000;130(4):477-482. 14. Alió JL, Piñero DP, Plaza-Puche AB, Chan MJR. Visual outcomes and optical performance of a monofocal intraocular lens and a new-generation multifocal intraocular lens J Cataract Refract Surg. 2011;37(2):241-250.

15. Alió JL. Comparison of the visual and intraocular optical performance of a refractive multifocal IOL with rotational asymmetry and an apodized diffractive multifocal IOL. J Refract Surg 2012;28(2):100.

16. Thibos LN, Applegate RA, Schwiegerling JT, Webb R. Standards for reporting the optical aberrations of eyes. J Refract Surg 2002;18(5):S652-S660.

17. McAlinden C, McCartney M, Moore J. Mathematics of zernike polynomials: A review. Clin Experiment Ophthalmol 2011;39(8):820-827.

18. Norrby S. Sources of error in intraocular lens power calculation. J Cataract Refract Surg 2008;34(3):368-376. 
19. Hayashi K, Manabe S, Yoshida M, Hayashi H. Effect of astigmatism on visual acuity in eyes with a diffractive multifocal intraocular lens. J Cataract Refract Surg $2010 ; 36(8): 1323-1329$.

20. Dick HB, Krummenauer F, FAU - Schwenn O, et al. Objective and subjective evaluation of photic phenomena after monofocal and multifocal intraocular lens implantation. Ophthalmology 1999 Oct;106(10):1878-86.

21. de Wit DW, Diaz J, Moore TCB, Moutari S, Moore JE. Effect of position of near addition in an asymmetric refractive multifocal intraocular lens on quality of vision. $\mathrm{J}$ Cataract Refract Surg 2015;41(5):945-955.

22. Elkady B, Alió JL, Ortiz D, Montalbán R. Corneal aberrations after microincision cataract surgery. J Cataract Refract Surg 2008;34(1):40-45. 


\section{Legends}

Figure 1. Diagram displaying the relationship between the position of the MIOL and the various categorised angles of residual astigmatism. The vertical axis of the MIOL (reading segment inferiorly and nasally displaced) is represented by the line at 135 degrees in the right eye and 45 degrees in the left eye. Top row: Angles from 0 to 22.5 degrees and 68 to 112.5 in both the right and left eye cross the vertical axis of the MIOL obliquely and are categorised together in the oblique group. Middle row. Angles from 23 to 67.5 in the right eye and 113 to 157.5 in the left eye cross the MIOL perpendicularly and are categorised together in the perpendicular group. Bottom row. Angles from 113 to 157.5 in the right eye and 23 to 67.5 in he left eye cross the MIOL perpendicularly and are categorised together in the parallel group.

Figure 2a. Assessment of the relationship between the residual refractive astigmatism and UDVA, 6 months postoperatively. Linear regression analysis demonstrates a weak relationship between residual refractive astigmatism and UDVA of 234 eyes. (UDVA = uncorrected distance visual acuity; $D=$ dioptres)

Figure $\mathbf{2 b}$. Linear regression analysis demonstrates a weak relationship between the defocus equivalent and UDVA of 234 eyes at the 6 month postoperative assessment. (UDVA = uncorrected distance visual acuity; D = dioptres)

Figure 3. Histogram showing the mean overall individual symptom scores for different magnitudes of residual refractive astigmatism at the 6 months postoperative assessment for 234 eyes. The $\mathrm{x}$-axis indicates the questioned symptom against the 
average responses ( $0=$ not at all, $1=$ a little, $2=$ quite, $3=$ very $)$ on the $y$-axis for each of the four categorised groups of residual refractive astigmatism. A higher average score indicates the patient is more affected by the symptom.

Figure 4. Histogram showing the mean overall QOV scores for different magnitudes of residual refractive astigmatism at the 6 months postoperative assessment for 234 eyes. The QOV is rated out of 10 , with 0 being the worst and 10 being the best. There was no significant difference between groups with varying magnitudes of residual refractive astigmatism, $P=0.28 . \quad(Q O V=$ quality of vision; $D=$ dioptres)

Figure 5. Histogram showing the mean overall QOV scores for different angles of residual corneal astigmatism in relation to the position of the MIOL. Eyes had corneal astigmatism of greater than $0.50 \mathrm{D}$ at the 6 months postoperative assessment. The QOV is rated out of 10 , with 0 being the worst and 10 being the best. There was no significant difference between groups with varying angles of residual corneal astigmatism, $\mathrm{P}=0.43$. (QOV = quality of vision) 
Synopsis file

This study provides vital information on the effect of residual astigmatism on the Lentis Mplus MIOL where it was found that increasing magnitudes did not significantly affect postoperative patient satisfaction. 


\section{Figure 1}

Click here to download high resolution image
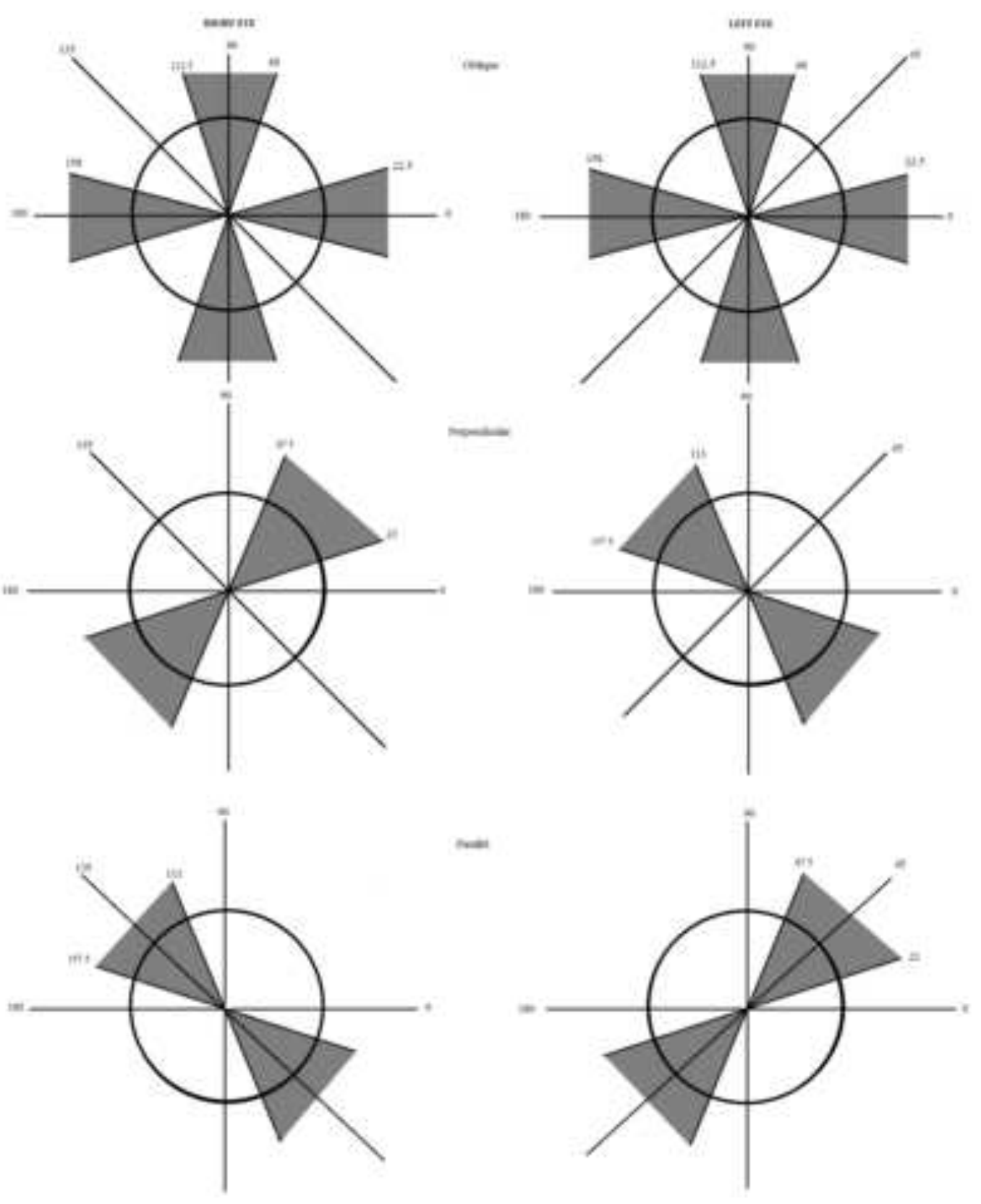
Click here to download high resolution image

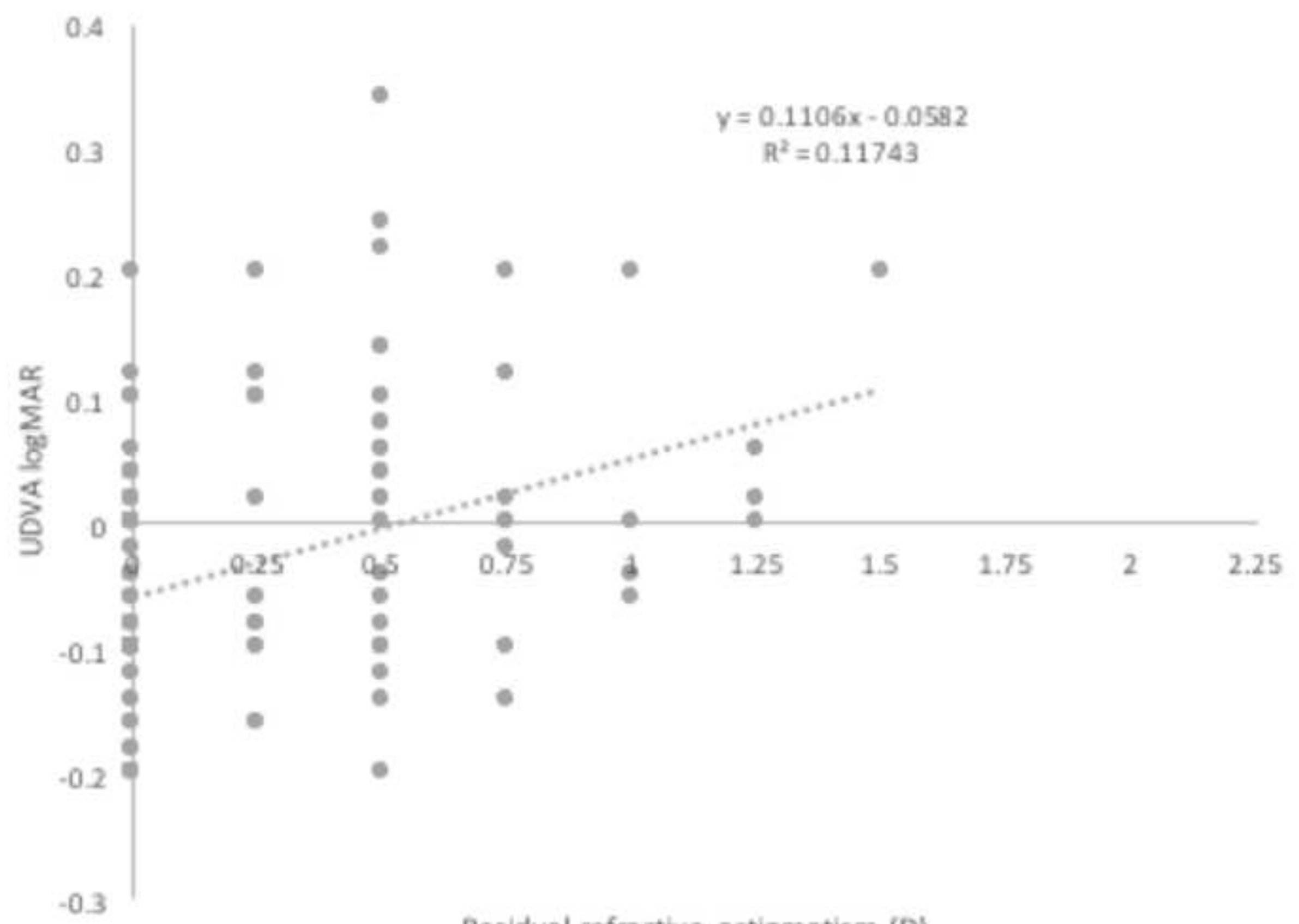

Residual refractive astigmatism (D) 


\section{Figure 2}

Click here to download high resolution image

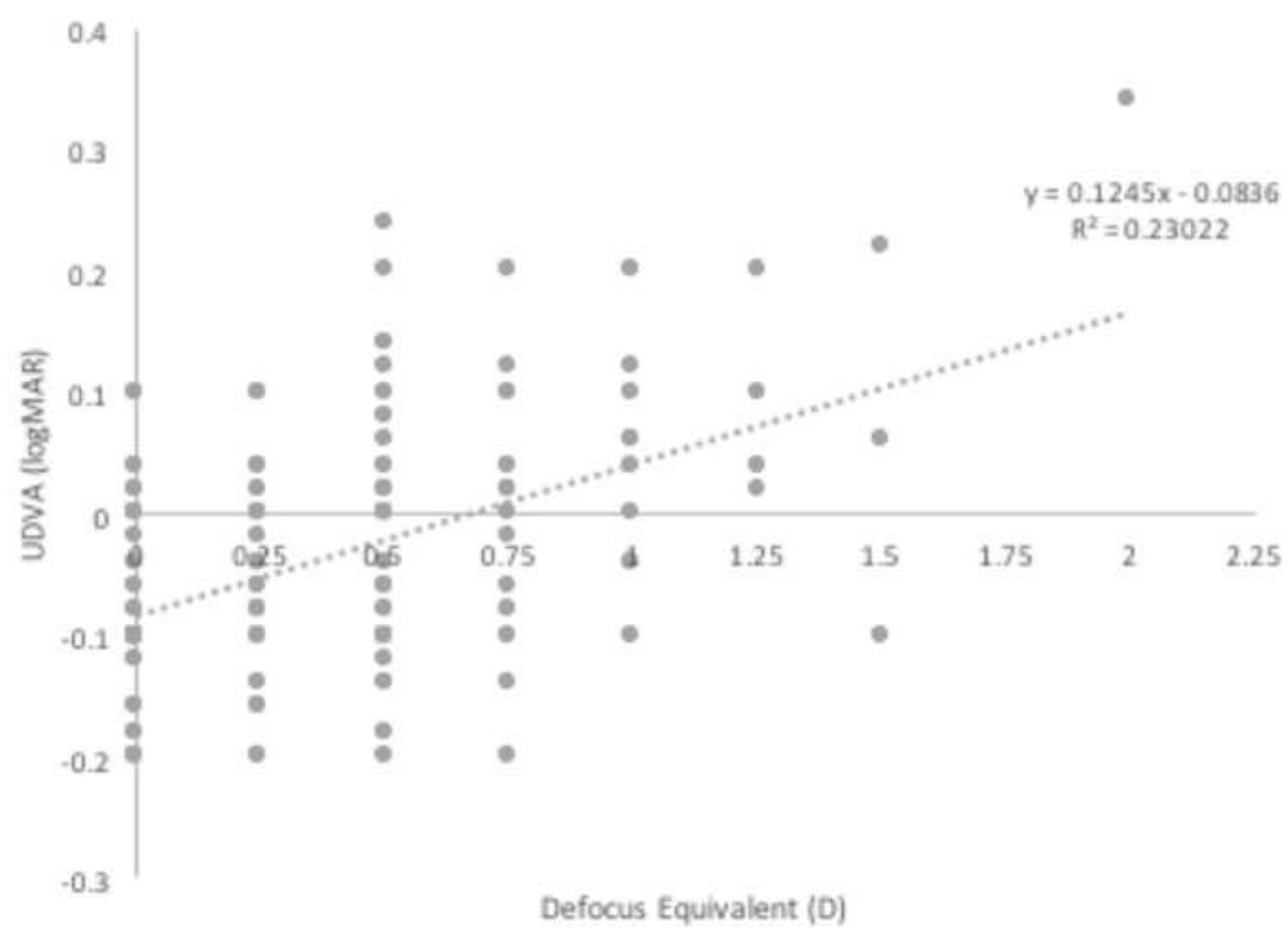


Click here to download high resolution image

3

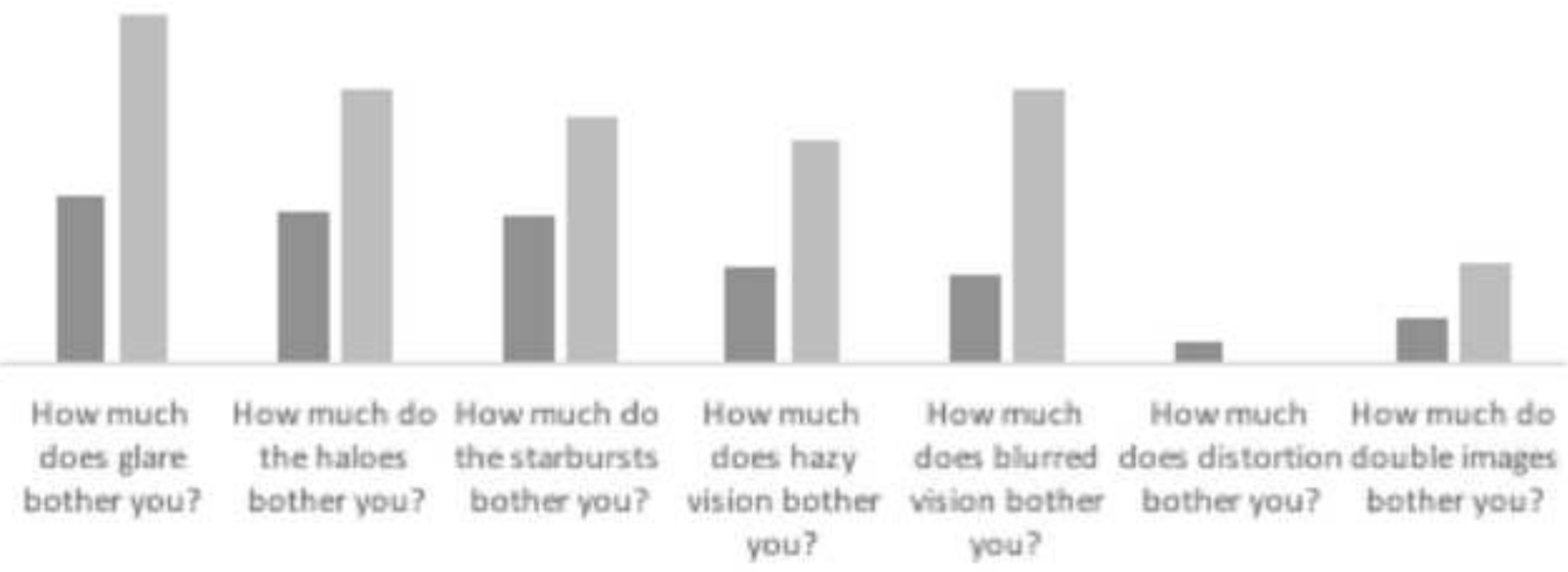


Figure 4

Click here to download high resolution image

10

9

8

7

6

$\sum^{\frac{2}{8}} 5$

3

2

1

0
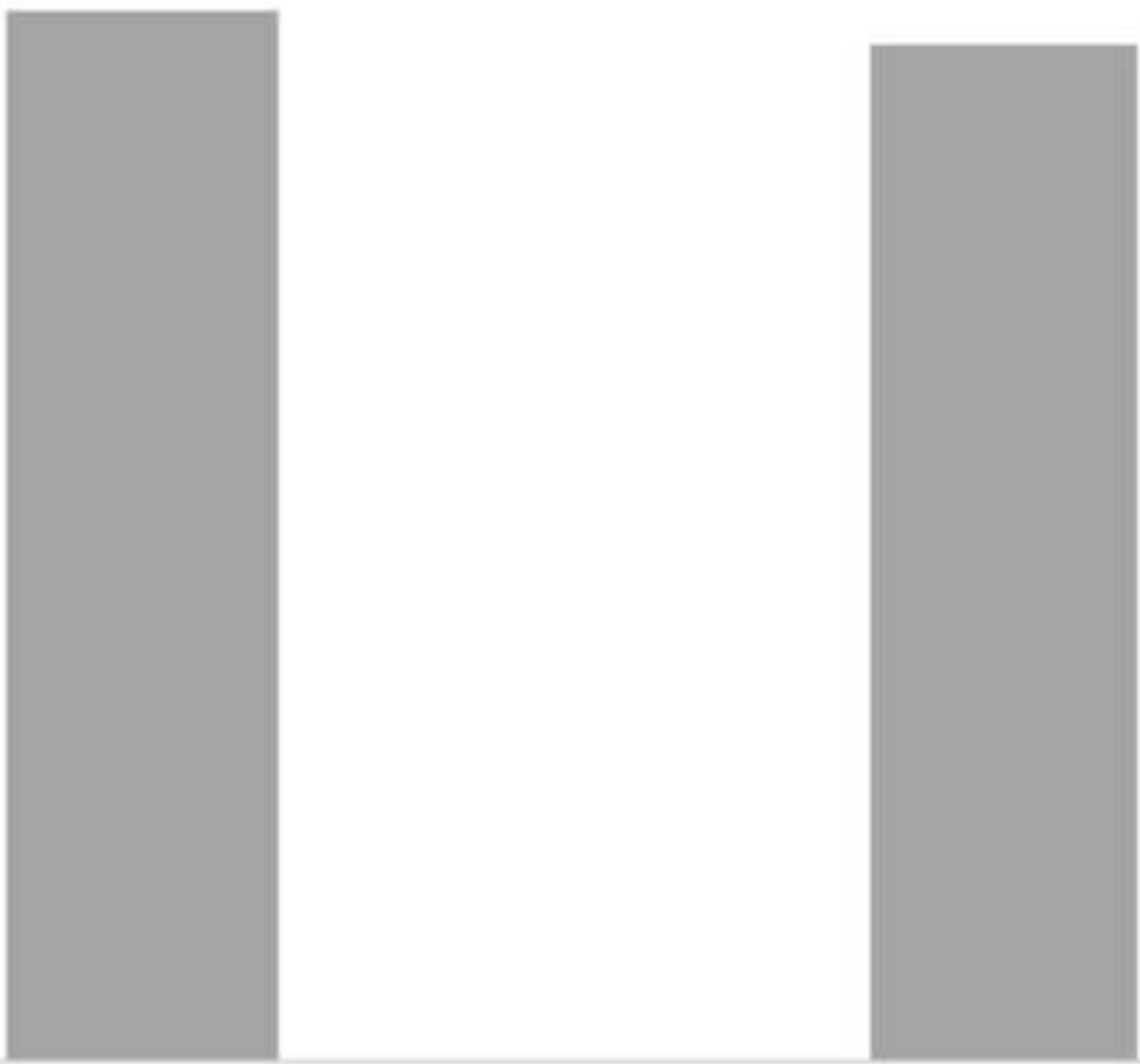

$\leq 0.500$

$>0.500$

Residual Refractive astigmatism (D) 
Figure 5

Click here to download high resolution image

9

0
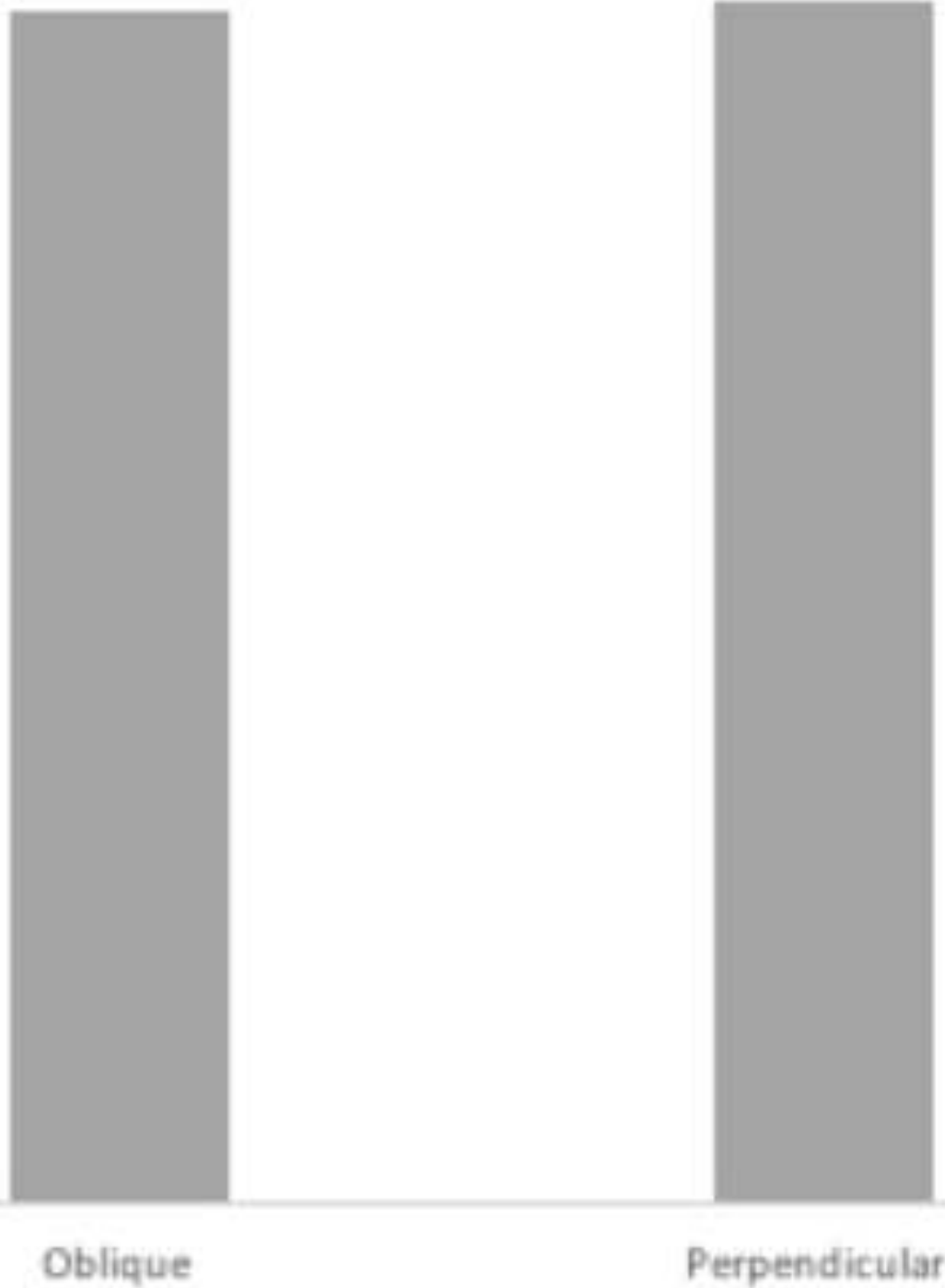

Perpendiculat

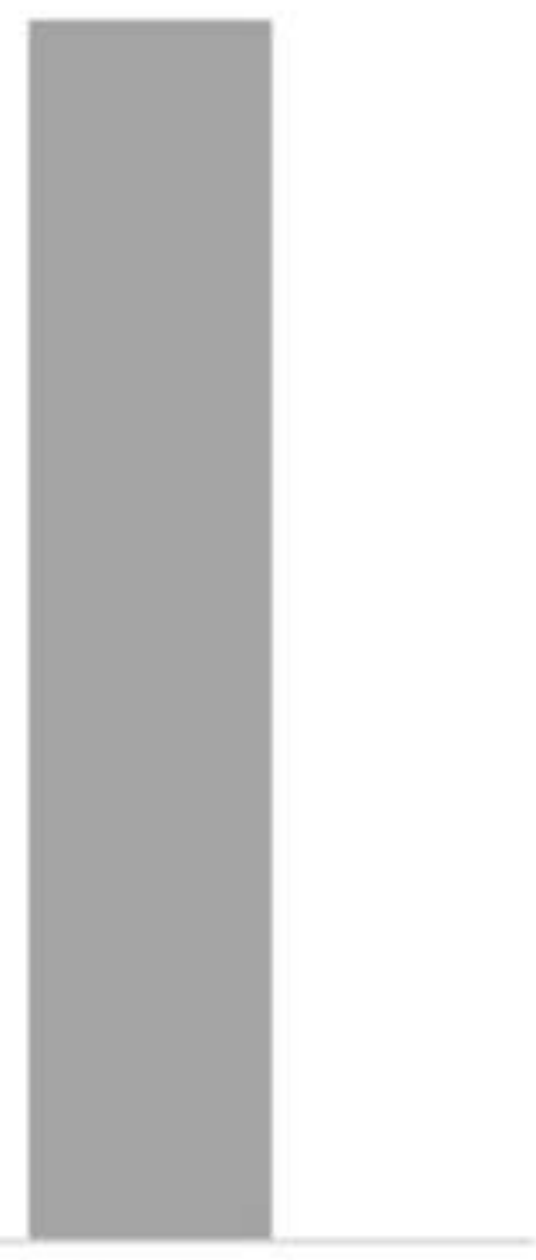


Table 1 Demographics

\section{Demographics}

Patients (n)

Male, n (\%)

$48(41)$

Female, $n$ (\%)

69 (59)

Age (y)

Mean $\pm S D^{*}$

$64 \pm 8.31$

Median

64

Range

44,87

Sphere (D十)

Mean \pm SD

Median

$0.41 \pm 3.83$

1.50

Range

$-16.50,5.75$

Cylinder (D)

$-0.56 \pm 0.56$

Mean \pm SD

$-0.50$

Median

$-2.25,0$

\section{LogMAR CDVA††}

Mean \pm SD

$0.01 \pm 0.12$

Median

0

Range

$-0.20,0.60$

${ }^{*} S D=$ standard deviation; $\uparrow D=$ dioptres; $\dagger+C D V A=$ corrected distance visual acuity 
Table 2

Between group comparisons of objective outcomes with different magnitudes of residual refractive astigmatism at the second postoperative assessment ( 6 months).

$$
\leq 0.50 D^{*}(n=216) \quad>0.50 D(n=18)
$$

P Value

LogMAR

\begin{tabular}{|c|c|c|c|}
\hline $\begin{array}{l}\text { UDVA } \dagger \\
\text { Mean } \pm \text { SD } \dagger \dagger\end{array}$ & $-0.05 \pm 0.09$ & $0.02 \pm 0.10$ & 0.003 \\
\hline $\begin{array}{l}\text { Range } \\
\text { Sphere (D) }\end{array}$ & $-0.20,0.34$ & $-0.14,0.20$ & \\
\hline Mean \pm SD & $0.08 \pm 0.38$ & $0.51 \pm 0.47$ & 0.001 \\
\hline $\begin{array}{l}\text { Range } \\
\text { Defocus } \\
\text { equivalent (D) }\end{array}$ & $-1.50,1.50$ & $-0.25,0.75$ & \\
\hline Mean \pm SD & $0.31 \pm 0.34$ & $0.83 \pm 0.24$ & $<0.001$ \\
\hline $\begin{array}{l}\text { Range } \\
\text { UNVA§ (M } \\
\text { notation) }\end{array}$ & $0,2.00$ & $0.50,1.25$ & \\
\hline Mean \pm SD & $0.60 \pm 0.17$ & $0.64 \pm 0.23$ & 0.35 \\
\hline $\begin{array}{l}\text { Range } \\
\text { UIVAll (M } \\
\text { notation) }\end{array}$ & $0.32,1.60$ & $0.40,1.25$ & \\
\hline Mean \pm SD & $0.96 \pm 0.24$ & $1.10 \pm 0.38$ & 0.15 \\
\hline $\begin{array}{l}\text { Range } \\
{ }^{*} D=\text { dioptres; } \dagger \\
\text { deviation; } \S U N \\
\text { intermediate vis }\end{array}$ & $\begin{array}{l}0.50,2.00 \\
=\text { uncorrecte } \\
\text { ncorrected n€ } \\
\text { uity }\end{array}$ & $\begin{array}{l}0.80,2.00 \\
\text { ual acuity; †† } \\
y ; \text {; } \| U I V A=\end{array}$ & \\
\hline
\end{tabular}




\section{Table 3}

Between group comparisons of objective outcomes with different magnitudes of corneal astigmatism at the second postoperative assessment ( 6 months).

\begin{tabular}{|c|c|c|c|c|c|}
\hline & $\begin{array}{l}\leq 0.50 D^{*} \\
(n=99)\end{array}$ & $\begin{array}{l}0.51 D \text { to } 0.75 D \\
(n=53)\end{array}$ & $\begin{array}{l}0.76 D \text { to } 1.001 \\
(n=41)\end{array}$ & $>1.00 D(n=41)$ & P Value \\
\hline $\begin{array}{l}\text { LogMAR } \\
\text { UDVA } \dagger\end{array}$ & & & & & \\
\hline $\begin{array}{l}\text { Mean } \pm \\
\text { SD†† }\end{array}$ & $-0.07 \pm 0.08$ & $-0.05+0.09$ & $0 \pm 0.08$ & $0 \pm 0.11$ & $<0.001$ \\
\hline $\begin{array}{l}\text { Range } \\
\text { Sphere } \\
\text { (D) }\end{array}$ & $-0.20,0.20$ & $-0.20,0.24$ & $-0.16,0.20$ & $-0.20,0.34$ & \\
\hline $\begin{array}{l}\text { Mean } \pm \\
\text { SD }\end{array}$ & $0.10 \pm 0.34$ & $0.13 \pm 0.46$ & $0.16 \pm 0.42$ & $0.06 \pm 0.45$ & 0.72 \\
\hline $\begin{array}{l}\text { Range } \\
\text { Defocus } \\
\text { equivalent } \\
\text { (D) }\end{array}$ & $-0.50,1.25$ & $-1.00,1.50$ & $-0.50,1.25$ & $-1.50,1.00$ & \\
\hline $\begin{array}{l}\text { Mean } \pm \\
\text { SD }\end{array}$ & $0.28 \pm 0.30$ & $0.37 \pm 0.43$ & $0.39 \pm 0.33$ & $0.43 \pm 0.43$ & 0.11 \\
\hline $\begin{array}{l}\text { Range } \\
\text { UNVA§ (M } \\
\text { notation) }\end{array}$ & $0,1.25$ & $0,1.50$ & $0,1.25$ & $0,2.00$ & \\
\hline $\begin{array}{l}\text { Mean } \pm \\
\text { SD }\end{array}$ & $0.58 \pm 0.16$ & $0.62 \pm 0.20$ & & & 0.14 \\
\hline $\begin{array}{l}\text { Range } \\
\text { UIVAll (M } \\
\text { notation) }\end{array}$ & $0.40,1.25$ & $0.32,1.25$ & $0.40,1.60$ & $0.40,0.80$ & \\
\hline $\begin{array}{l}\text { Mean } \pm \\
\text { SD }\end{array}$ & $0.95 \pm 0.20$ & $0.97 \pm 0.28$ & $0.99 \pm 0.20$ & $1.04 \pm 0.38$ & 0.45 \\
\hline Range & $0.80,1.60$ & $0.63,1.60$ & $0.80,1.25$ & $0.50,2.00$ & \\
\hline
\end{tabular}


Table 4

Between group comparisons of objective outcomes for different angles of corneal astigmatism greater than $0.50 \mathrm{D}$ at the second postoperative assessment ( 6 months or greater).

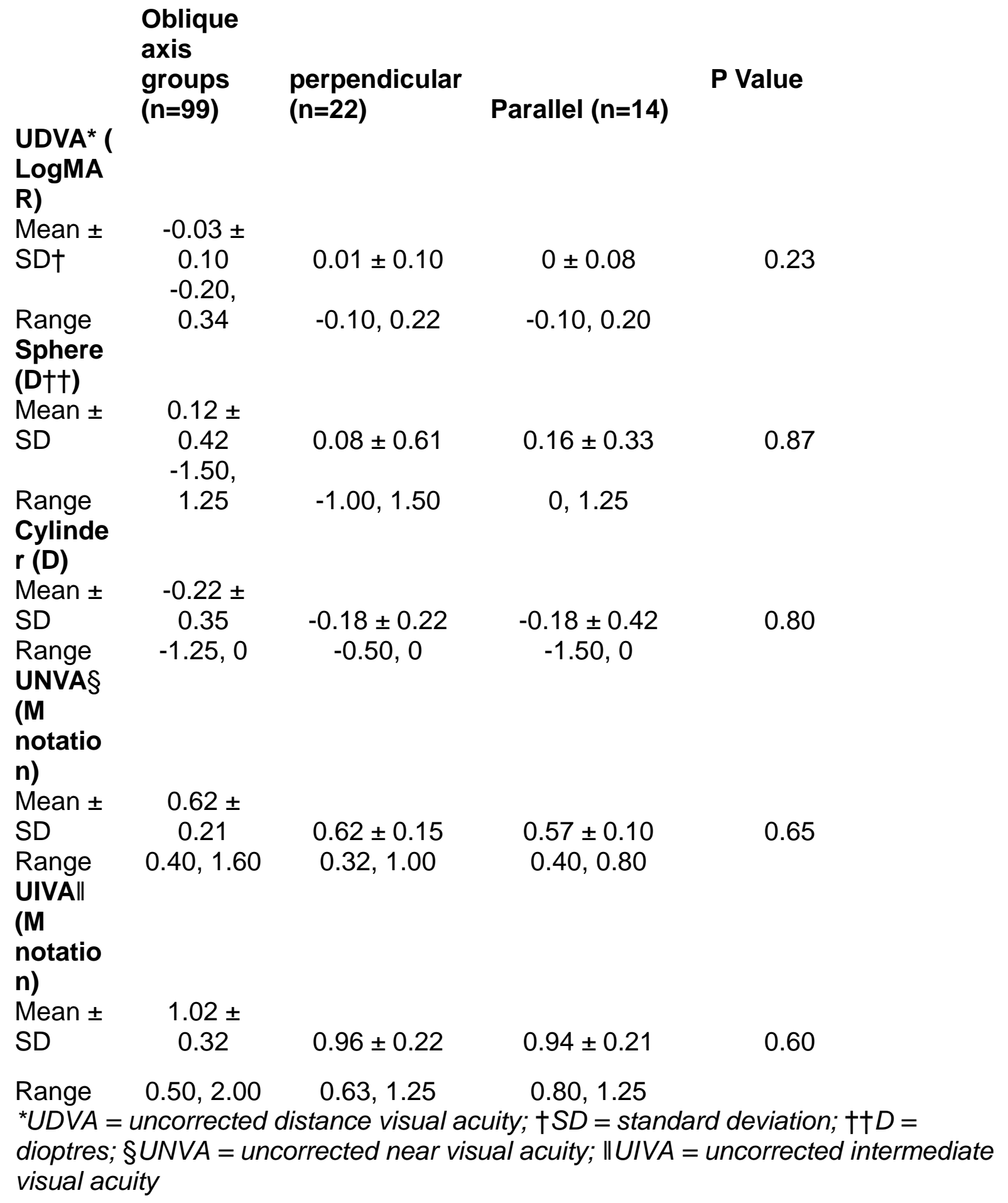

